\title{
SÍNDROME DE ALSTRÖM HALLGREN
}

\section{ALSTRÖM HALLGREN SYNDROME}

\author{
PUERTAS-BORDALLO D ${ }^{1}$, DE-DOMINGO-BARÓN B ${ }^{2}$, LOZANO-VÁZQUEZ M², \\ ESCUDERO-DÍAZ C ${ }^{3}$, RUIZ-FALCÓ ROJAS ML ${ }^{4}$, FERNÁNDEZ-FERNÁNDEZ J²
}

\section{RESUMEN}

Introducción: El Síndrome de Alström es una enfermedad autosómica recesiva. Se conoce un gen (ALMS1) asociado al síndrome, caracterizado por ceguera causada por distrofia de conos y bastones, sordera sensorial, resistencia a la insulina, obesidad, y cardiopatías.

Caso clínico: Niño de cuatro años que tras una parada cardiorrespiratoria es diagnosticado de cardiomiopatía dilatada. Comienza con nistagmus y fotofobia. Se le realiza exploración oftalmológica y ERG, siendo los resultados compatibles con un Síndrome de Alström.

Discusión: El diagnóstico en estos casos es clínico. El diagnóstico de certeza con técnicas moleculares es posible en un $25-40 \%$ de casos. El tratamiento es sintomático.

Palabras claves: Distrofia de conos y bastones. Diabetes mellitus. Cardiopatía. Obesidad. ALSM1.

\begin{abstract}
Introduction: Alstrom-Hallgren syndrome is an inherited condition in which the transmission of a double dose of a mutated gene leads to specific clinical findings. To the present time there has been only one gene detected which leads to this syndrome, the ALMS1 gene. Mutation of this gene leads to progressive blindness due to photoreceptor dystrophy, progressive sensorineural hearing loss, insulin resistant diabetes, morbid obesity and cardiologic abnormalities.
\end{abstract}

Clinical Case: We present the case of a four-yearold male who, after a cardiopulmonary shutdown in the fourth month of life, was diagnosed with a dilated cardiomyopathy. Nystagmus and photophobia followed, and, after ophthalmologic exploration and an electroretinogram, the results were consistent with Alström syndrome. The appropriate genetic studies were then performed.

Discussion: The diagnosis in this case was considered basically because of its uncommon clinical features, and the fact a multidisciplinary approach was used in its evaluation. We were only able to confirm the diagnosis by molecular biology techniques, with this resulting in the correct diagnosis in

\footnotetext{
Recibido: 21/3/06. Aceptado: 23/7/07.

Sección de Oftalmología/Estrabología del Hospital Infantil Universitario Niño Jesús de Madrid. España.

1 Doctor en Medicina.

2 Licenciado en Medicina. MIR de Oftalmología. Complejo Hospitalario Universitario de Santiago de Compostela. España.

3 Licenciado en Medicina. Servicio de Alergología.

4 Licenciada en Medicina. Sección de Neurología.

Correspondencia:

Diego Puertas Bordallo

Sección de Oftalmología/Estrabología del Hospital Infantil Universitario Niño Jesús

Avenida Menéndez Pelayo, 65

28009 Madrid

España

E-mail: dpuertas.hnjs@salud.madrid.org
} 
$25-40 \%$ of cases. Treatment is symptomatic and the prognosis extremely variable (Arch Soc Esp Oftalmol 2007; 82: 649-652).

Key words: Photoreceptor dystrophy, Diabetes Mellitus, Cardiomyopathy, Obesity, ALSM1.

\section{INTRODUCCIÓN}

El Síndrome de Alström tiene una prevalencia muy baja, hay descritos aproximadamente 350 casos. El primero de ellos fue descrito por un médico sueco llamado Carl Henry Alström en 1959. Son pacientes con una alteración genética recesiva en el brazo corto del cromosoma 2-(2p12-13) (1). Puede afectar a todas las razas, pero la mayor parte de los casos han sido descritos en Holanda y Suecia (fig. 1).

Clínicamente se caracteriza por una serie de síntomas secuenciales. De los primeros suelen ser la cardiomiopatía y las alteraciones visuales que pueden incluso presentarse durante el primer año de vida.

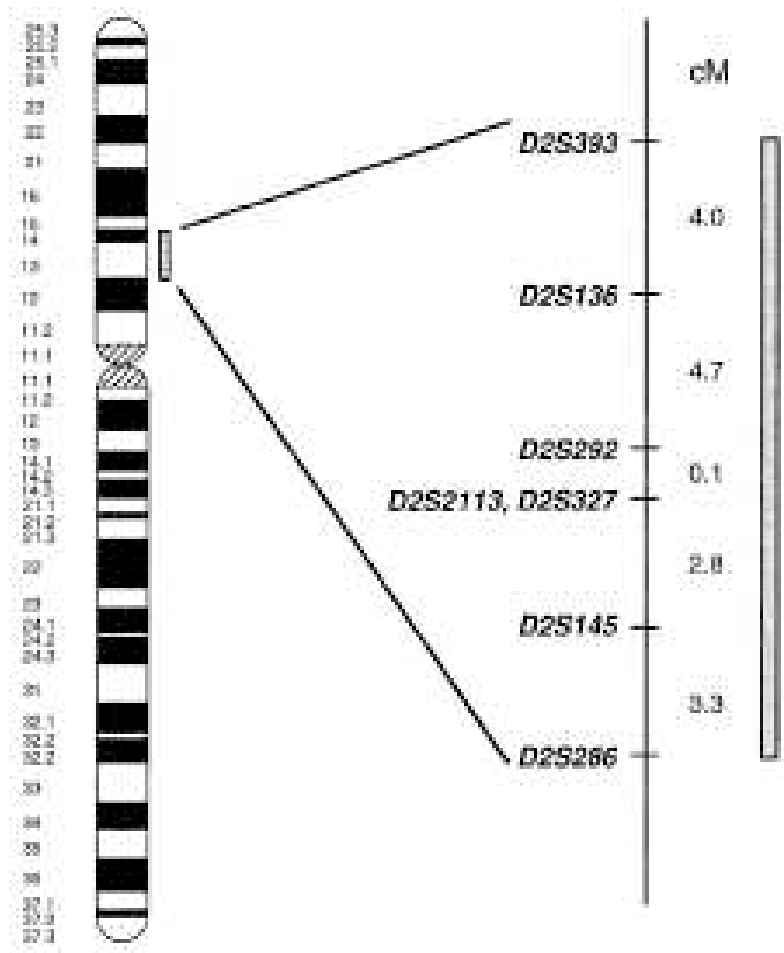

Fig. 1: Mapa genético del cromosoma $2 p$ en el Síndrome de Alström (2).
Las alteraciones visuales consisten en una distrofia de conos y de bastones junto a nistagmus, fotofobia y pérdida progresiva de la visión central y periférica que puede evolucionar a ceguera en la primera década de la vida.

La sordera suele debutar a los cuatro años y la obesidad en la adolescencia, momento en el que la resistencia a la insulina va desembocando en diabetes mellitus.

El diagnóstico de este síndrome se basa en los hallazgos clínicos y en el estudio genético molecular. No existe ninguna prueba diagnóstica característica. Es necesaria una analítica de sangre, que revelará una hiperglucemia y una hipertrigliceridemia, una analítica de orina, que mostrará un aumento de los niveles de ácido úrico, y un examen oftalmológico completo. El diagnóstico prenatal es posible en algunos casos.

No existe ningún tratamiento curativo específico para esta enfermedad. El objetivo del tratamiento es corregir y aliviar alguno de los síntomas que aparecen y el control de la diabetes.

\section{CASO CLÍNICO}

Varón, hijo único, nacido a las cuarenta semanas de gestación por cesárea. Como antecedentes familiares destacar que su madre presentaba diabetes mellitus no insulinodependiente desde los 17 años y no existir consaguinidad entre los padres.

A los cuatro meses de vida, sufre una parada cardiorrespiratoria, (diagnosticado de cardiomiopatía dilatada) (1). Durante su ingreso hospitalario comienza con fotofobia y nistagmus intermitente, y se recomienda revisión oftalmológica en su lugar de origen.

El niño presenta un retraso psicomotor por lo que se solicita una Resonancia Magnética Nuclear (RMN) y comienza desde el año de vida con trata- 
miento de estimulación precoz, consiguiendo en ocho meses los objetivos propuestos. En la RMN se observan pequeñas áreas de aumento de señal en T2 y FLAIR en las regiones periatriales y sustancia blanca temporal (fig. 2).

A los dos años es remitido a nuestro Hospital para estudio ecográfico y oftalmológico. Se solicita un ERG que muestra ausencia de respuestas, y Potenciales Evocados Visuales (PEV) normales. Oftalmoscópicamente muestra nistagmus con fotofobia intensa. El segmento anterior y el fondo de ojo son normales (fig. 3).

Como el diagnóstico clínico es sugestivo de Síndrome de Alström, se solicita un estudio genético en el que tras analizar los exones 10, 16 y un segmento del exón 8 del gen ALMS-1 (3) donde se encuentran las mutaciones descritas hasta el momento, amplificado por PCR y secuenciación automatizada, no se detectan mutaciones, sin embargo, estos resultados no excluyen el diagnóstico.

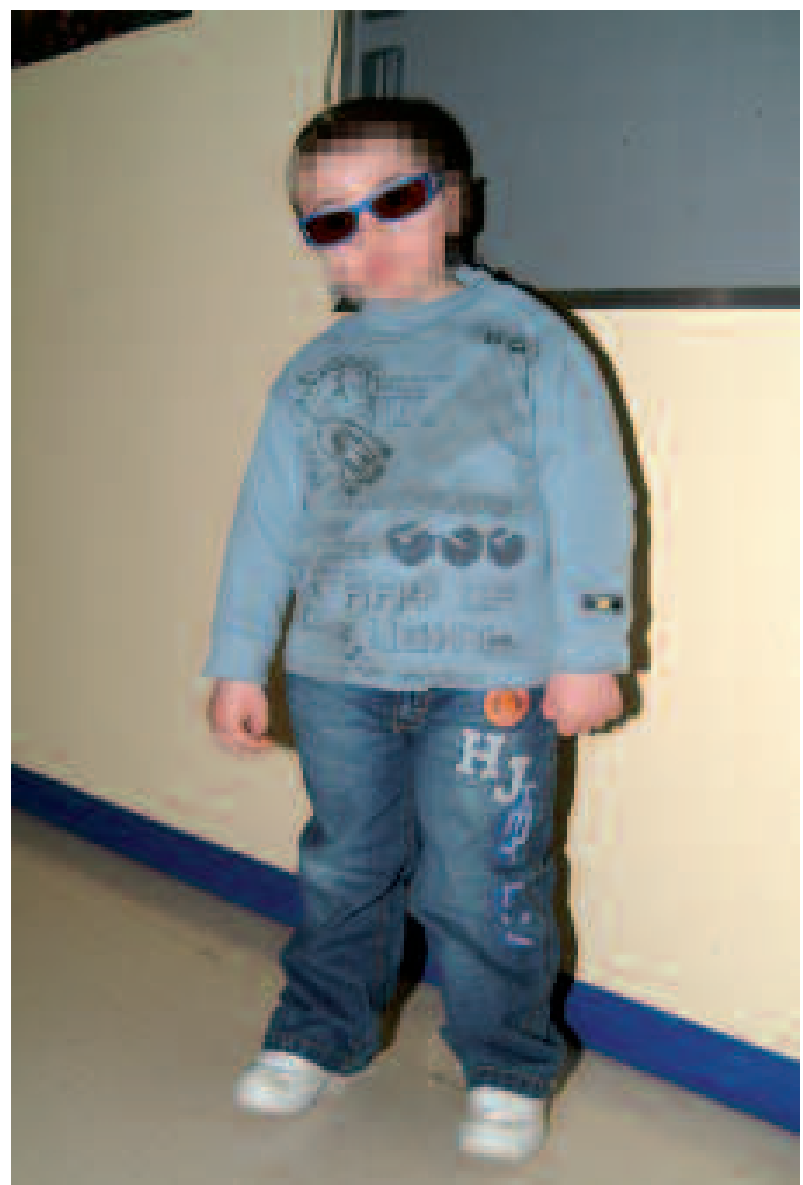

Fig. 2.

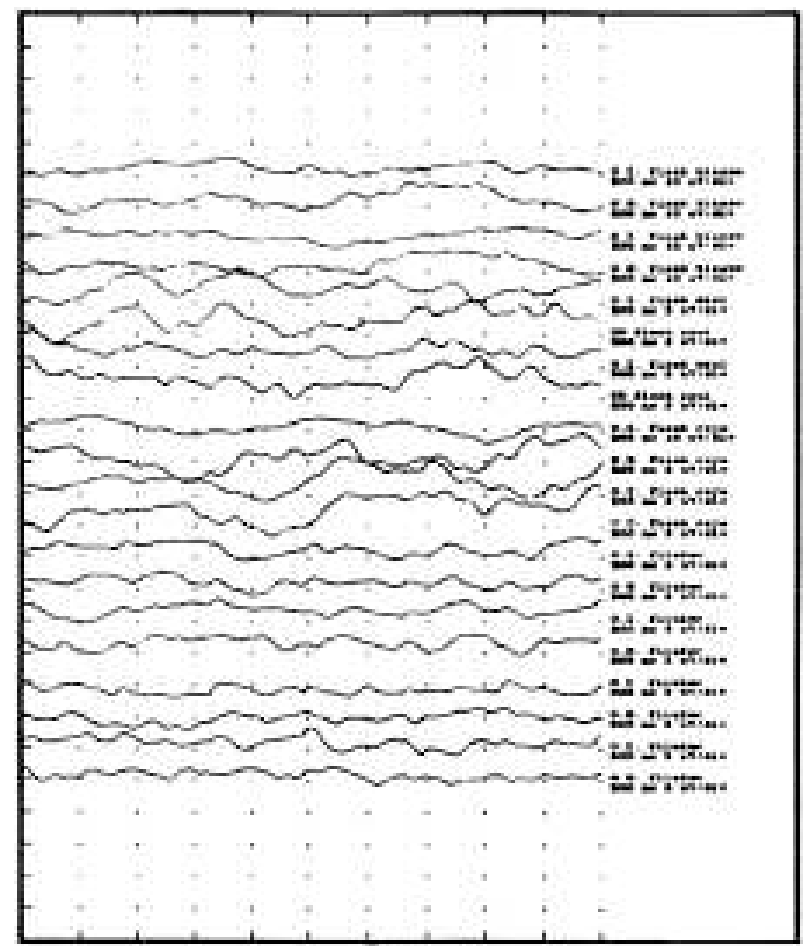

Fig. 3.

\section{DISCUSIÓN}

El Síndrome de Alström es poco frecuente. Se caracteriza por la presencia de distrofia de conos y bastones, obesidad, sordera sensorial, resistencia a la insulina y alteraciones cardíacas (tabla I).

\section{Tabla I.}

\section{Signos y síntomas}

Fotofobia y nistagmus en la infancia

Degeneración retiniana de conos y bastones

Síntomas de resistencia insulínica / DMNID

Obesidad infantil

Pérdida de audición bilateral

Miocardiopatía dilatada

Nefropatía crónica con disfunción tubular

Otros signos y síntomas menos frecuentes

Acantosis nigricans

Hipogonadismo con desarrollo sexual posterior normal Hipotiroidismo

Escoliosis

Talla corta

Hipertriglicerinemia e hiperuricemia

Asma y problemas respiratorios

Distonía muscular

Hipertensión portal e HTA 
Esta distrofia de conos y bastones se empieza a manifestar desde el primer año de vida con fotofobia y nistagmus en un fondo de ojo normal pero con alteraciones en el ERG (1). Con el tiempo aparecerá una atrofia coriorretiniana.

Nuestro caso presenta resistencia a la insulina, obesidad, hipogenitalismo, y alteraciones cardiacas. No manifestando sordera neurosensorial, que por otra parte suele empezar de forma lenta y progresiva afectando a las frecuencias altas a partir de los cuatro años de edad. Asimismo la función renal era normal.

El diagnóstico es clínico, y sólo en un 25-40\% de los casos, se ponen de manifiesto las alteraciones genéticas ubicadas en el único gen conocido, el ALMS-1 (3,4) (fig. 4).

El Síndrome de Bardet-Biedl presenta fascies característica y polidactilia, una malformación no observable en el Síndrome de Älstrom. Además los síntomas visuales son más tardíos apareciendo a los 8 años de edad.

La acromatopsia es una entidad retiniana y se manifiesta como disminución de agudeza visual, fotofobia, nistagmus, escotoma central, y pérdida de la discriminación de los colores.

La amaurosis congénita de Leber (LCA) es una distrofia retiniana con afectación cardiaca y neuro-

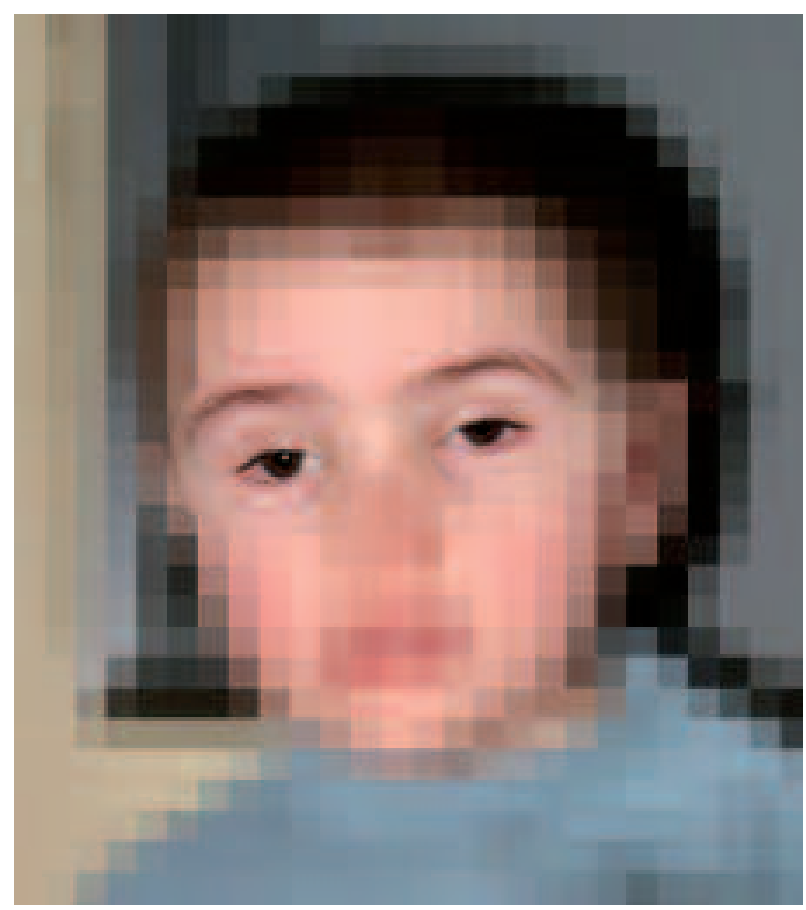

Fig. 4.

\section{Tabla II. Guías de monitorización}

Evaluación oftalmológica, ERG

Audiometría anual

BMI

Test de función cardíaca, ECG y ecocardiograma anual

Control de glucemia

Presión arterial

ECO hepática

Analítica de sangre: función renal, hepática y perfil lipídico

Función tiroidea

Función gastrointestinal

Función gonadal ( LH, FSH, testosterona )

Pruebas de capacidad pulmonar

Evaluación neurológica

lógica. El signo óculo-digital es característico. El ERG no es detectable. En nuestro paciente se observan alteraciones endocrinas como obesidad, hipogonadismo y resistencia a la insulina. No presentando anomalías neurológicas.

El seguimiento clínico es importante y se utilizan guías de actuación para la monitorización de la enfermedad (tabla II).

Desde el punto de vista oftalmológico es recomendable el uso de lentes tintadas con filtros solares y el aprendizaje del Braille.

El tratamiento endocrinológico engloba el control de la diabetes, la hiperlipemia y las deficiencias hormonales.

El pronóstico y evolución de esta enfermedad es variable (5).

\section{BIBLIOGRAFÍA}

1. Michaud JL, Heon E, Guilbert F, Weill J, Puech B, Benson L, et al. Natural history of Alstrom syndrome in early childhood: onset with dilated cardiomyopathy. J Pediatr 1996; 128: 225-229.

2. Collin GB, Marshall JD, Boerkoel NF, Levin AV, Weksberg R, Greenberg J, et al. Alstrom syndrome: further evidence for linkage to human chromosome 2p13. Hum Genet 1999; 105: 474-479.

3. Collin GB, Cyr E, Bronson R, Marshall JD, Gifford EJ, Hicks W, et al. Alms1-disrupted mice recapitulate human Alstrom syndrome. Hum Mol Genet 2005; 14: 2323-2333.

4. Deeble VJ, Roberts E, Jackson A, Lench N, Karbani G, Woods CG. The continuing failure to recognise Alstrom syndrome and further evidence of genetic homogeneity. $J$ Med Genet 2000; 37: 219.

5. Collin GB, Marshall JD, Ikeda A, So WV, Russell-Eggitt I, Maffei $P$, et al. Mutations in ALMS1 cause obesity, type 2 diabetes and neurosensory degeneration in Alstrom syndrome. Nat Genet 2002; 31: 74-78. 